\title{
An Electrochemical Evaluation of Synthesized Coumarin-Azo Dyes as Potential Corrosion Inhibitors for Mild Steel in $1 \mathrm{M}$ HCl Medium
}

\author{
Mohd Hamizi Yusoff ${ }^{1}$, Mohamad Nurul Azmi ${ }^{1,2, *}$, Mohd Hazwan Hussin ${ }^{1, *}$, Hasnah Osman ${ }^{1}$, Pandian \\ Bothi Raja ${ }^{1}$, Afidah Abdul Rahim ${ }^{1}$, Khalijah Awang ${ }^{3}$ \\ ${ }^{1}$ School of Chemical Sciences, Universiti Sains Malaysia, 11800 Minden, Pulau Pinang, Malaysia \\ ${ }^{2}$ Malaysian Institute of Pharmaceuticals \& Nutraceuticals, NIBM, Ministry of Science, Technology \\ and Innovation (MOSTI), Pulau Pinang, 11700 Malaysia \\ ${ }^{3}$ Department of Chemistry, Faculty of Science, University of Malaya, 50603 Kuala Lumpur \\ *E-mail: mnazmi@usm.my; mhh@usm.my
}

doi: $10.20964 / 2020.12 .43$

Received: 2 July 2020 / Accepted: 8 October 2020 / Published: 31 October 2020

The anti corrosion properties of mild steel were studied in $1.0 \mathrm{M} \mathrm{HCl}$ medium with azo-coumarin dyes inhibitor by electrochemical impedance and potentiodynamic polarization measurements. The azocoumarin dyes 8-10 were synthesized by coupling reaction between diazonium salt of aniline derivatives with 4-hydroxycoumarin under basic condition. The result showed that inhibition efficiency was found to increase (shown average $I E>80 \%$ ), with increasing the concentration of azocoumarin dyes, and their adsorption over mild steel surface found to obey Langmuir adsorption isotherm. Furthermore, the Langmuir adsorption isotherm parameters made evident that corrosion inhibition proceeds through physisorption mode of interaction. After corrosion evaluation, mild steel's surface morphology was screened via SEM - EDX analysis which showed an improved surface in the presence of azo-coumarin dye derivatives.

Keywords: Corrosion inhibitor; Azo-coumarin dyes; Mild steel; Electrochemical impedance.

\section{FULL TEXT}

(C) 2020 The Authors. Published by ESG (www.electrochemsci.org). This article is an open access article distributed under the terms and conditions of the Creative Commons Attribution license (http://creativecommons.org/licenses/by/4.0/). 